\title{
Synthesis of zinc oxide nanoparticles using tea leaf extract and its application for solar cell
}

\author{
PRASANTA SUTRADHAR and MITALI SAHA* \\ Department of Chemistry, National Institute of Technology, Agatrala 799046, Tripura, India
}

MS received 14 July 2014

\begin{abstract}
We report the synthesis of zinc oxide ( $\mathrm{ZnO}$ ) nanoparticles and its composite with natural graphite (NG) powder for application in solar cell. $\mathrm{ZnO}$ nanoparticles were synthesized using green tea leaf extract as non-toxic and eco-friendly reducing material under microwave irradiation. The formation of $\mathrm{ZnO}$ nanoparticles was monitored by the colour changes during the reaction. The synthesized $\mathrm{ZnO}$ nanoparticles were characterized by particle size analyzer (dynamic light scattering), scanning electron microscope, UV-visible spectroscopy, atomic force microscope and fluorescence spectroscopy. The average particle size of the $\mathrm{ZnO}$ nanoparticles was found to be $26 \mathrm{~nm}$. The synthesized $\mathrm{ZnO}$ nanoparticles were further used to prepare $\mathrm{ZnO}$ /NG composite material with commercially available NG powder. The current-voltage $(I-V)$ characteristics of thin film of $\mathrm{ZnO} / \mathrm{NG}$ nanocomposite were investigated. $J_{\mathrm{SC}}$ (short-circuit photocurrent), $V_{\mathrm{OC}}$ (open-circuit photovoltage), FF (fill factor) and $\eta$ (efficiency of the solar cell) were measured for $\mathrm{ZnO} / \mathrm{NG}$ nanocomposite. Interestingly, the cell showed a good power conversion efficiency of $3.54 \%$ with high stability.
\end{abstract}

Keywords. Tea leaf; $\mathrm{ZnO}$; NG; microwave; solar cell.

\section{Introduction}

Zinc oxide $(\mathrm{ZnO})$ is being extensively used in the fabrication of solar cells, namely quantum dot-sensitized solar cells. $^{1-3}$ It has many technological applications, because of its exceptional optical and electrical properties, such as thin film transistors, gas sensors, transparent conductor, biomedical and piezoelectric application. ${ }^{4-8}$ It is expected to be an alternating material for $\mathrm{TiO}_{2}$ because of its properties such as being environment friendly, stability and that, it can be synthesized into different shapes and sizes very easily. It is well known that $\mathrm{ZnO}$ is one of the most important semiconductor materials with direct wide bandgap (3.2-3.37 eV) and good transparency ${ }^{9}$ at room temperature. Besides, due to large exciton binding energy of $60 \mathrm{meV},{ }^{10}$ it has potential applications in optoelectronic devices such as solar cells. ${ }^{11}$ Thin films of $\mathrm{ZnO}$ can be prepared by various techniques like sputtering, ${ }^{12}$ chemical vapour deposition, ${ }^{13}$ laser ablation, ${ }^{14}$ sol-gel, ${ }^{15}$ spray pyrolysis, ${ }^{16}$ from clear emulsion of monodispersed $\mathrm{ZnO}$ nanocrystals ${ }^{17,18}$ etc.

Recently, there is a growing necessity to develop environmentally friendly methods that does not use toxic materials in the synthesis procedures. Till now, a large number of physical, chemical and biological methods are available to synthesize different type of nanoparticles. ${ }^{12-16}$

Synthesis of nanoparticles using different parts of the plants is quite novel, leading to truly green chemistry which

\footnotetext{
*Author for correspondence (mitalichem71@gmail.com)
}

is effective also at a very affordable cost, ${ }^{17-20}$ as there is no need of high pressure, energy, temperature and toxic chemicals. More recently, some of the researchers have described that the use of eco-friendly benign materials like leaf extract (aloe barbadensis), ${ }^{21}$ bacteria $^{22}$ and fungus ${ }^{23}$ for the synthesis of $\mathrm{ZnO}$ nanoparticles offers numerous advantages of ecofriendliness and compatibility for pharmaceutical and other biomedical applications.

In continuation of our earlier research work on green synthesis of metal nanoparticles, ${ }^{24}$ the present study describes the rapid synthesis of $\mathrm{ZnO}$ nanoparticles in mass level, using green tea leaf extract under microwave irradiation. These $\mathrm{ZnO}$ nanoparticles were further used to prepare thin film of composite material with natural graphite (NG) powder to study its suitable application in solar cells.

\section{Materials and methods}

Tea leaf was collected from tea garden, Tripura. Zinc nitrate, NG powder and polystyrene (PS) were purchased from Sigma Aldrich. Double distilled water was used throughout the experiments.

\subsection{Preparation of tea leaf extract}

A quantity of $20 \mathrm{~g}$ of finely grounded tea leaf was dissolved in $200 \mathrm{ml}$ of water and boiled for around $3 \mathrm{~h}$. After cooling at room temperature, it was centrifuged for $15 \mathrm{~min}$ and filtered. The filtrate was stored at $5-10^{\circ} \mathrm{C}$ for further experiments. 


\subsection{Preparation of $\mathrm{ZnO}$ nanoparticles using tea leaf extract}

Zinc nitrate was used as precursor for the synthesis of $\mathrm{ZnO}$ nanoparticles. A ratio of $1: 3$ of zinc nitrate and tea leaf extract was mixed and the solution was subjected to microwave irradiation at $540 \mathrm{~W}$, which produced brownishblack precipitate after $7 \mathrm{~min}$. The precipitate was filtered and then dried at hot air oven for 4-5 h. The possible mechanism of the formation of $\mathrm{ZnO}$ nanoparticles from tea leaf extract is shown in scheme 1 .

\subsection{Characterization of $\mathrm{ZnO}$ nanoparticles}

The $\mathrm{ZnO}$ nanoparticles obtained was characterized by dynamic light scattering (DLS; nanotrac wave W3222), UVvis spectroscopy (Shimadzu 1800), scanning electron microscope (SEM; JSM-6360 JEOL), atomic force microscopy (AFM; multimode V8) and florescence spectroscopy (Perkin Elmer LS 55).

\subsection{Preparation of thin film of $\mathrm{ZnO} / \mathrm{NG}$ nanocomposite}

Thin film of $\mathrm{ZnO} / \mathrm{NG}$ nanocomposite was prepared by mixing 1 : 1 ratio of $\mathrm{ZnO}$ nanoparticles and $\mathrm{NG}$ powder with small amount of PS using xylene as solvent. The solution mixture was sonicated for $30 \mathrm{~min}$ followed by stirring at $60^{\circ} \mathrm{C}$ for 4 h. A drop of the resultant slurry was spread on a glass and a thin film was obtained using another glass slide. PS was chosen because of its chemical stability and excellent solubility in ordinary solvents, which helped in making the thin film.

\subsection{Photovoltaic characteristics}

The photovoltaic measurements of thin film of $\mathrm{ZnO} / \mathrm{NG}$ nanocomposite were carried out using a PGSTAT 101 solar simulator with an irradiance of $100 \mathrm{~mW} \mathrm{~cm}^{-2}$. The currentvoltage $(I-V)$ characteristics of the cell were measured by applying external potential bias to the cell and measuring the generated photocurrent. The monochromator was incremented through the visible spectrum to generate the IPCE (incident photon to current conversion efficiency). Parameters such as $J_{\mathrm{SC}}$ (short-circuit photocurrent), $V_{\mathrm{OC}}$ (opencircuit photovoltage), FF (fill factor) and $\eta$ (efficiency of the solar cell) were measured for $\mathrm{ZnO} / \mathrm{NG}$ nanocomposite.

\section{Results and discussion}

The green tea leaf extract was used as reducing as well as stabilizing agent for $\mathrm{ZnO}$ nanoparticles. The microwave irradiation accelerated the processes and the reaction was completed in a very short period of time $(7 \mathrm{~min})$. The reaction does happen in the absence of microwave heating, but it takes almost 4-5 h at room temperature. This further gave strong evidence for the involvement of polyphenol contents of tea leaf in the rapid biosynthesis and for the stability of metal nanoparticles in the aqueous medium. ${ }^{25}$ The reaction mechanism in scheme 1 showed that, $\mathrm{ZnO}$ nanoparticles can be obtained through the reduction of $\mathrm{Zn}^{+2}$ using tea leaf that contains epigallocatechin gallate (EGCG), which acts as both the reducing and capping agent. EGCG is a highly water-soluble compound with strong polarity. As such, the structure of EGCG gave enough reducibility to convert $\mathrm{Zn}^{2+}$ ions into $\mathrm{Zn}(0)$ nanoparticles. As illustrated in scheme 1, EGCG served as a stable (electron + proton) donor in interactions, and was converted into the radical ion called 'semihydro-EGCG' and then dehydro-EGCG. Dehydro-EGCG and EGCG together constituted the redox<smiles>C[C+]C(C)C(=O)c1cc(O)c(O)c(C(=O)OCC)c1</smiles><smiles>O=C(O)c1ccc(O)c(O)c1</smiles><smiles>O=C([O-])C1=CC(O)C(=O)C(O)=C1</smiles>

Semidehydro-EGCG<smiles>O=C(O)C1=CC(=O)C(=O)C(O)=C1</smiles><smiles>CC(C)CC(C)C</smiles><smiles>O=C([O-])C1C=C(O)C(=O)C(C(=O)O)C1</smiles>

$\mathrm{Zn}^{2+}+2 \mathrm{e}$

$\mathrm{Zn}^{0}+\operatorname{Air}\left(\mathrm{O}_{2}\right)$ $\mathrm{ZnO}$

Scheme 1. Reaction for the formation of $\mathrm{ZnO}$ nanoparticles. 
system, which was sufficient to reduce $\mathrm{Zn}^{2+}$ to $\mathrm{Zn}$. Besides, it should be noted that EGCG has also played the role of stabling agent during the reaction process. The lone pair electrons in the polar groups of EGCG can occupy two sp orbits of the zinc ion to form a complex compound. The EGCG was capped with zinc ions, then synthesized $\mathrm{Zn}(0)$ nanoparticles through reduction of $\mathrm{Zn}^{2+}$ inside the nanoscopic templates. In the presence of nanoscopic templates, small zinc nanoparticles were easily formed. The other explanation may be attributed to the dispersion effect of the oxidation product of EGCG on the zinc nanoparticles after the completion of the reduction reaction. EGCG was converted into dehydro-EGCG through oxidation.

The formation of $\mathrm{ZnO}$ nanoparticles from tea leaf extract was initially monitored by the colour change occurring during the reaction period, as shown in figure 1 . The colour change arises due to the excitation of surface plasmon resonance in the metal nanoparticles, indicating the formation of $\mathrm{ZnO}$ nanoparticles. Figure 2 shows the DLS of the nanoparticles, which confirmed the average size of the $\mathrm{ZnO}$ nanoparticles to be around $26 \mathrm{~nm}$. The SEM image clearly indicated the formation of spherical $\mathrm{ZnO}$ nanoparticles with

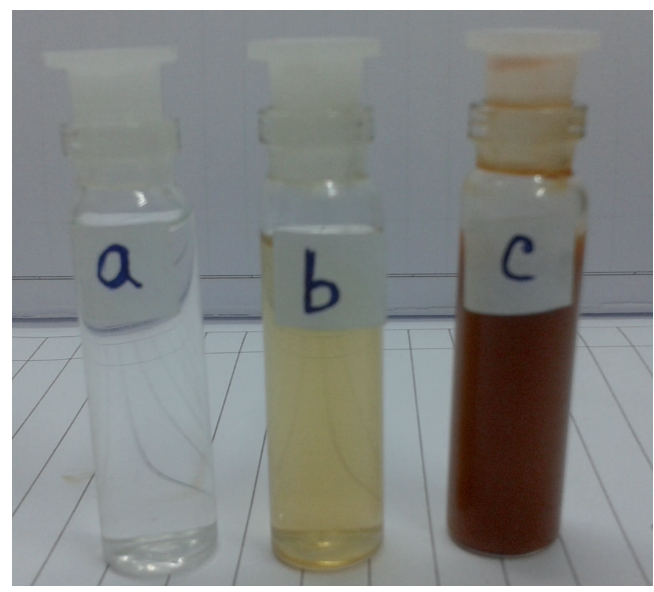

Figure 1. (a) Aqueous solution of zinc nitrate; (b) tea leaf extract and (c) colour of the solution after reaction.

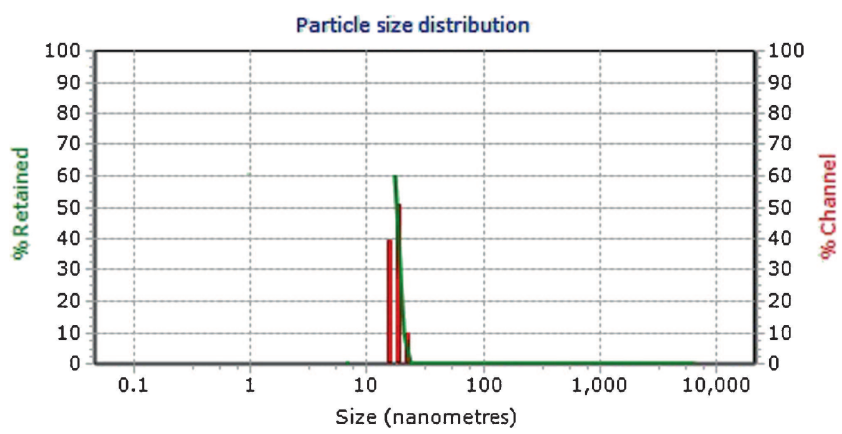

Figure 2. Particle analyzer histogram of as-prepared $\mathrm{ZnO}$ nanoparticles. the size ranging between 20 and $50 \mathrm{~nm}$ (figure 3). The UVvisible spectrum of $\mathrm{ZnO}$ showed the absorption peak at 345 $\mathrm{nm}$ (figure 4), which matched with the expected value of $\mathrm{ZnO}$ nanoparticles. ${ }^{26}$

AFM showed the topo-graphic image of well-dispersed $\mathrm{ZnO}$ nanoparticles (figure 5). The luminescence of $\mathrm{ZnO}$ nanoparticles is of particular interest from viewpoints of both physical and applied aspects. Figure 6 showed the room temperature photoluminescence spectrum of the $\mathrm{ZnO}$ nanoparticles with excitation peak at $438 \mathrm{~nm}$. The excitation peak corresponded to the band to band transition, which also confirmed the blue shift in the bandgap of $\mathrm{ZnO}$ nanoparticles. Figure 7 shows the UV-vis spectra of thin film of $\mathrm{ZnO} / \mathrm{NG}$ nanocomposite, where two characteristics peaks were found at 231 and $272 \mathrm{~cm}^{-1}$ for NG powder and at $368 \mathrm{~cm}^{-1}$ for $\mathrm{ZnO}$ nanoparticles.

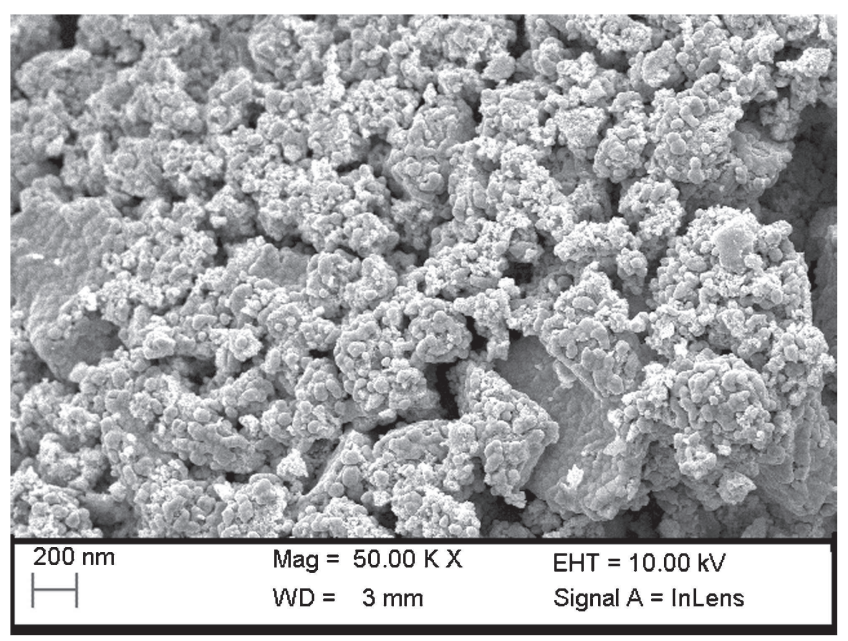

Figure 3. SEM image of $\mathrm{ZnO}$ nanoparticles.

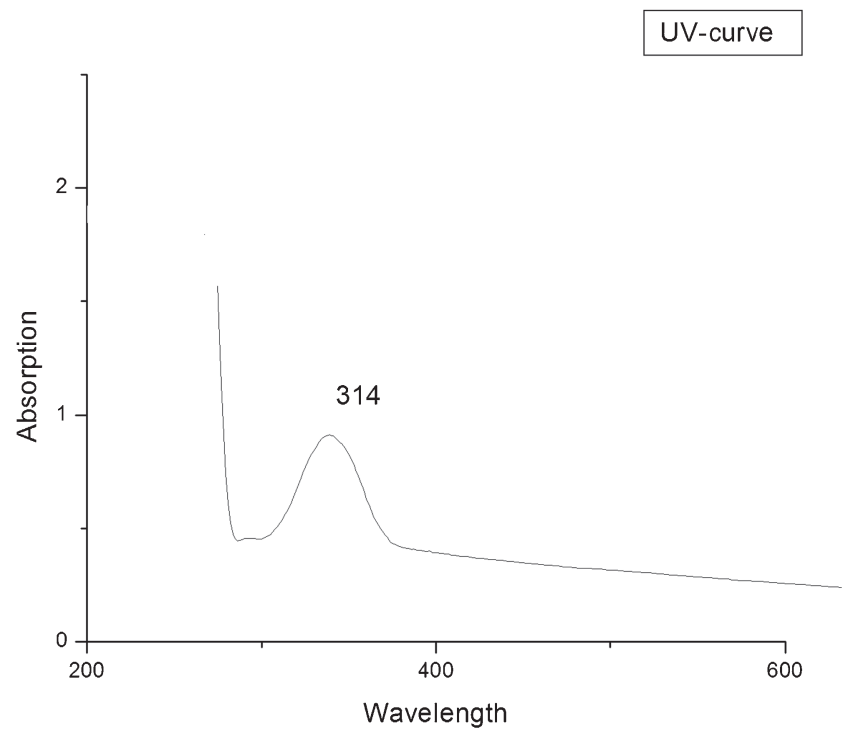

Figure 4. UV-vis spectra of $\mathrm{ZnO}$ nanoparticles. 


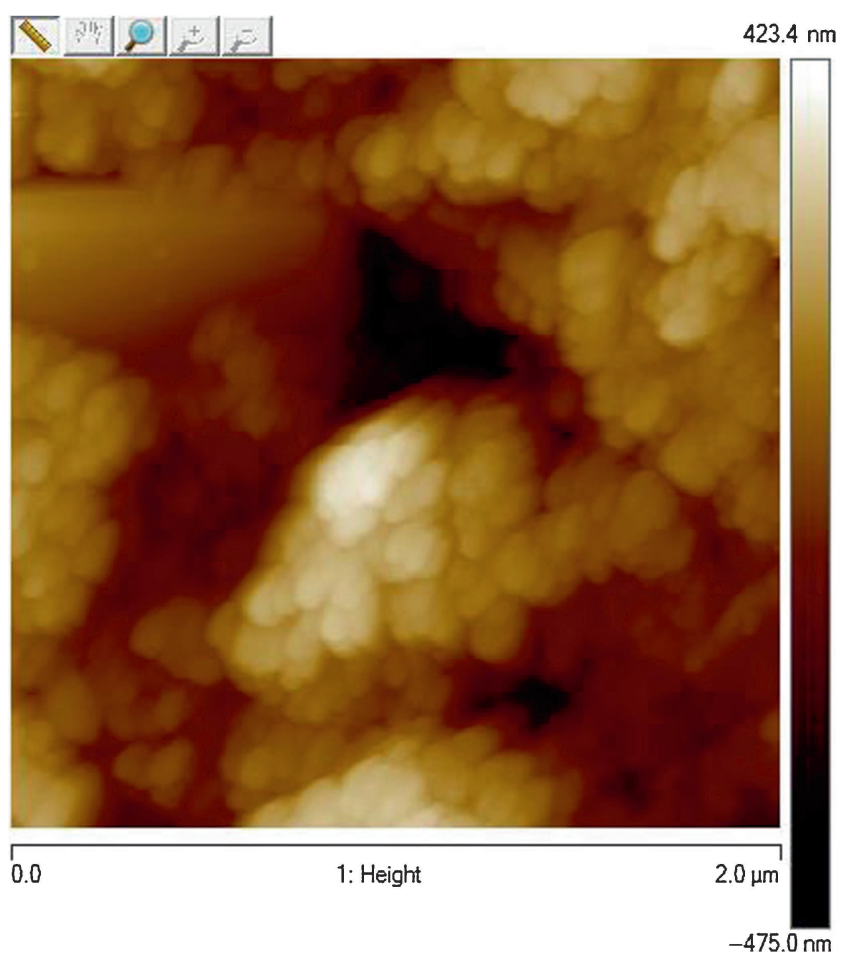

Figure 5. AFM of $\mathrm{ZnO}$ nanoparticles.

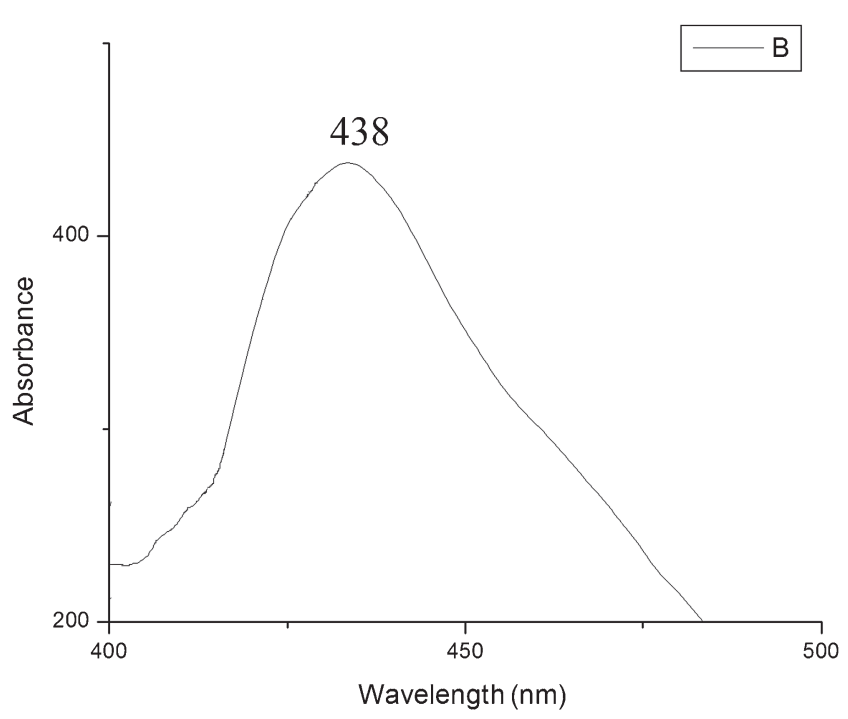

Figure 6. Florescence spectra of $\mathrm{ZnO}$ nanoparticles.

The photovoltaic measurements were carried out using two electrode systems. Xenon lamp was used as a light source and the incident light intensity was maintained at 100 $\mathrm{mW} \mathrm{cm}{ }^{-2}$. Figure 8 shows the photocurrent density-voltage measurements ( $J-V$ curves), which can be obtained by applying a potential scan, from $0 \mathrm{~V}$ (short-circuit conditions) to the open-circuit potential, under constant illumination.

The FF was calculated by

$$
\mathrm{FF}=V_{\mathrm{M}} J_{\mathrm{M}} / V_{\mathrm{oc}} J_{\mathrm{sc}} \cdot{ }^{27}
$$

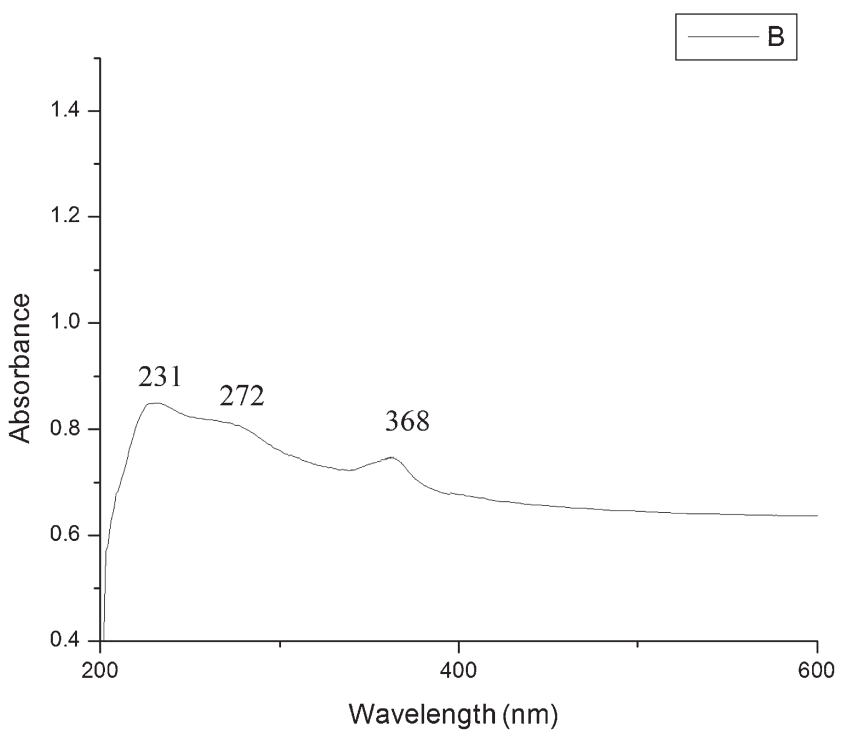

Figure 7. UV-vis spectra of $\mathrm{ZnO}$ nanocomposites.

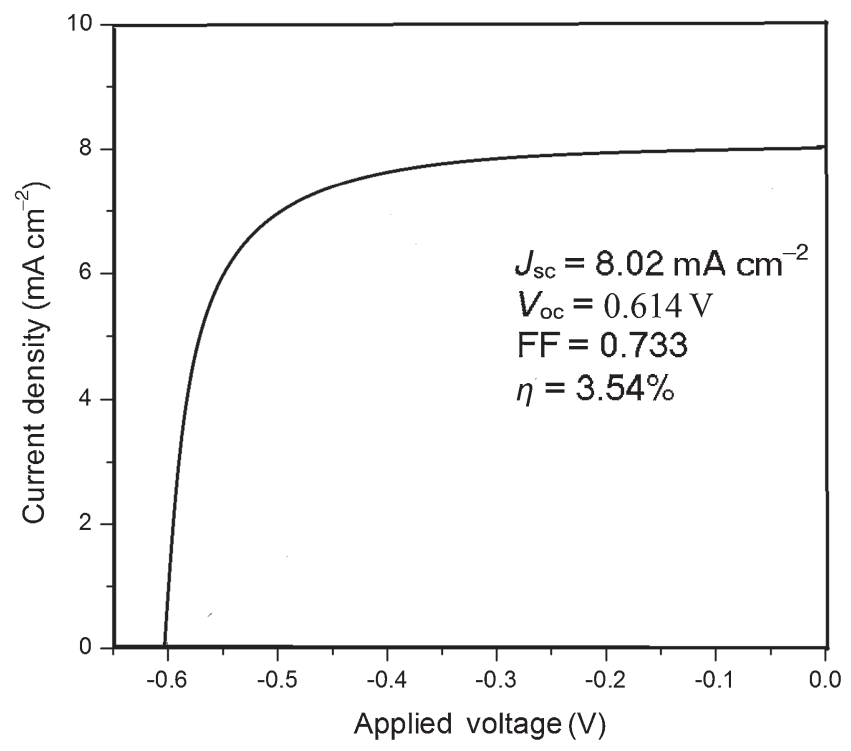

Figure 8. Current density vs. voltage curve.

Where $V_{\mathrm{M}}$ and $J_{\mathrm{M}}$ were photovoltage and photocurrent density for maximum power output, respectively.

Efficiency was calculated by

$$
H=V_{\mathrm{oc}} J_{\mathrm{sc}} \mathrm{FF} / P_{\text {in }}{ }^{27}
$$

Where $P_{\text {in }}$ is the power of incident white light from Xe lamp.

Under the irradiation of $100 \mathrm{~mW} \mathrm{~cm}^{-2}$, the $\mathrm{ZnO} / \mathrm{NG} \mathrm{com-}$ posite gave a short-circuit photocurrent $\left(J_{\mathrm{sc}}\right)$ of $8.02 \mathrm{~mA}$ $\mathrm{cm}^{-2}$, open-circuit photovoltage $\left(V_{\mathrm{oc}}\right)$ of $0.614 \mathrm{~V}$ and $\mathrm{FF}$ of 0.733 . Efficiency in the fabricated cell was measured as $3.54 \%$. The FF was about $73.3 \%$. Obviously the weak value of this cell was due to the low value of the FF and the efficiency. This may be due to the higher series resistance. ${ }^{28,29}$ 


\section{Conclusion}

In this paper, microwave-assisted green chemistry has been used for the synthesis of $\mathrm{ZnO}$ nanoparticles. A facile approach has been reported using green tea leaf extract, acting as reducing agent for the synthesis of $\mathrm{ZnO}$ nanoparticles of well-defined dimensions in bulk amount. This eliminated the need of toxic chemicals for the synthesis of nanoparticles. Besides, excellent reproducibility of these nanoparticles, without the use of any additional capping agent or stabilizer, will have a great advantage in comparison with microbial synthesis, avoiding all the tedious and hygienic complications. $\mathrm{ZnO}$ nanoparticles were successfully used to prepare thin film of $\mathrm{ZnO} / \mathrm{NG}$ composite material for photovoltaic application. Interestingly, this $\mathrm{ZnO} / \mathrm{NG}$ nanocomposite showed a significant efficiency of $3.54 \%$.

\section{Acknowledgements}

We express our gratitude to the Director, National Institute of Technology, Agartala, for allowing to publish the results. Financial assistance from CPRI, Bangalore, is greatly acknowledged.

\section{References}

1. Singh N, Mehra R M, Kapoor A and Soga T 2011 J. Renew. Sustain. Ener. 4013110

2. Wang J, Sallet V, Jomard F, Rego A M, Elamurugu E, Martins R and Fortunato E 2007 Thin Solid Films 5158785

3. Wang Z L 2004 J. Phys. Condens. Matter 16829

4. Nomura K, Ohta H, Ueda K, Kamiya T, Hirano M and Hosono H 2003 Science 3001269

5. Nakada T, Hirabayashi Y, Tokado T, Ohmori D and Mise T 2004 Sol. Energy 77739

6. Lee S Y, Shim E S, Kang H S, Pang S S and Kang J S 2005 Thin Solid Films 31437

7. Könenkamp R, Word R C and Schlegel C 2004 Appl. Phys. Lett. 856004
8. Sharma N, Kumar J, Thakur S, Sharma S and Shrivastava V 2013 Drug Invention Today 550

9. Dinguha Bao, Gu Haoshuang, Kuang and Anxiang 1998 Thin Solid Films 13237

10. Ehsan H Sabbar, Mustafa H Saleh and Mohammed Salih 2012 Int. J. Adv. Sci. Technol. 4489

11. Sinha S, Pan I, Chanda P and Sen S K 2009 J. Appl. Biosci. 19 1113

12. Liu J, Qiao H Q H and Lu G Q 2011 Small 7425

13. Grass L R N, Athanassiou E K and Stark W J 2010 Chem. Mater. 22155

14. Tiwari D K, Behari J and Sen P 2008 Curr. Sci. 95647

15. Mohanpuria P, Rana N K and Yadav S K 2008 J. Nanopart. Res. 10507

16. Honary S, Barabadi H, Gharaei-Fathabad E and Naghibi F 2012 Digest J. Nanomater. Biostruct. 7999

17. Capek I 2004 Adv. Colloid Interface Sci. 11049

18. Table A, Petit C and Pileni M P 1997 Chem. Mater. 9950

19. Yin B S, Ma H Y, Wang S Y and Chen S H 2003 J. Phys. Chem. B 1078898

20. Zhu J J, Liu S W, Palchik O, Koltypin Y and Gedanken A 2000 Langmuir 166396

21. Sangeetha G, Rajeshwari S and Venckatesh R 2011 Mater. Res. Bull. 462560

22. Jayaseelan C, Rahuman A A, Kirthi A V, Marimuthu S, Santhoshkumar T and Bagavan A 2012 Spectrochim. Act A Mol. Biomol. Spectrosc. 9078

23. Jain N, Bhargava A, Tarafdar J C, Singh S K and Panwar J A 2013 J. Appl. Microbiol. Biotechnol. 97859

24. Sutradhar P, Saha M and Maiti D 2014 J. Nanostruct. Chem. 486

25. Chandran S P, Chaudhary M and Pasricha R 2006 Biotechnol. Prog. 22577

26. Susan A, Ahmada B Mansor, Farideh Namvar and Rosfarizan Mohamad 2013 Materials 65942

27. Waltera Michael G, Rudineb Alexander B and Wamser Carl C 2010 J. Porphyrin Phthalocyanines 14759

28. Stanley A G 1975 Appl. Sol. State Sci. 5251

29. Ashour A, Ramadan A A, Abd EL-Hady K and Akl A A S 2005 J. Optoelectron. Adv. Mater. 71493 